Geograficando, vol. 14, n. ${ }^{\circ}$ 1, e035, junio 2018. ISSN 2346-898X

Universidad Nacional de La Plata.

Facultad de Humanidades y Ciencias de la Educación.

Departamento de Geografía

\title{
Humboldt y la construcción del paisaje hispanoamericano en Vues des cordillères (1810)
}

\author{
Amalia Chaves \\ Universidad Nacional de La Plata, Argentina \\ maiuskita@yahoo.com.ar
}

\section{Juan Cruz Margueliche}

Instituto de Investigaciones en Humanidades y Ciencias Sociales (IdIHCS) -

Universidad Nacional de La Plata, Argentina

jcruzmargueliche@gmail.com

Cita sugerida: Chaves, A. y Margueliche, J. C. (2018). Humboldt y la construcción del paisaje hispanoamericano en Vues des cordillères (1810). Geograficando 14 (1), e035. https://doi.org/10.24215/2346898Xe035

Recidido: 19 de marzo de 2018 - Aceptado: 11 de abril 2018 - Publicado: 31 de julio de 2018 


\section{Humboldt y la construcción del paisaje hispanoamericano en Vues des cordillères (1810).}

Humboldt and the Spanish American Landscape construction in Vues descordillères (1810)

Amalia Chaves

Universidad Nacional de La Plata, Argentina

maiuskita@yahoo.com.ar

Juan Cruz Margueliche

Instituto de Investigaciones en Humanidades y Ciencias Sociales (IdIHCS)

Universidad Nacional de La Plata, Argentina

jcruzmargueliche@gmail.com

\section{ReSUMEN:}

Sin duda, la labor de Alexander von Humboldt (Berlín, 1769-1859) representa un cambio de paradigma en la consideración del paisaje americano. Los viajeros (académicos e independientes) se acercaron a las lejanas tierras extranjeras cargados de representaciones de exotismo y de intervenciones (simbólicas y materiales) en los "nuevos" espacios. Analizaremos Vistas de las cordilleras y monumentos de los pueblos indígenas de América (1810), considerando las inflexiones y matices que adquieren, por una parte, la singularidad del paisaje de lo que luego se denominaría América Latina y, por otra, las aristas en tensión que configuran la otredad de los indígenas y su arte, a partir de criterios de belleza y bondad.

Palabras clave: Humboldt; Paisaje; Otredad.

\section{Abstract:}

Undoubtedly, the work of Alexander von Humboldt (Berlin, 1769-1859) represents a paradigm shift in the consideration of the American landscape. The travelers (academic and independent) approached the distant foreign lands charged with representations of exoticism and interventions (symbolic and material) in the "new" spaces. We will analyze Views of the mountain ranges and monuments of the indigenous peoples of America (1810), considering the inflections and nuances that acquire, on the one hand, the uniqueness of the landscape of what would later be called Latin America and, on the other, the edges in tension that form the otherness of the natives and their art, based on criteria of beauty and kindness.

KEYWORDS: Humboldt; Landscape; Otherness.

\section{INTRODUCCIÓN}

Sin duda, la labor de Alexander von Humboldt (Berlín, 1769-1859) representa un cambio de paradigma en la consideración del paisaje americano. Los viajeros (académicos e independientes) se acercaron a las lejanas tierras extranjeras cargados de representaciones de exotismo y de intervenciones (simbólicas y materiales) en los "nuevos" espacios. Analizaremos Vistas de las cordilleras y monumentos de los pueblos indígenas de América (1810), considerando las inflexiones y matices que adquieren, por una parte, la singularidad del paisaje de lo que luego se denominaría América Latina y, por otra, las aristas en tensión que configuran la otredad de los indígenas y su arte, a partir de criterios de belleza y bondad.

La obra de Humboldt se nutre de sus viajes, tanto de sus recorridos dentro de Europa (sobre todo por Prusia y Francia) como por los territorios no europeos. Por otra parte, su trabajo también se alimentó de diferentes itinerarios sociales a partir del contacto con las ideas de otros destacados científicos y artistas. La construcción del pensamiento humboldtiano se articula sobre un binarismo que se pronuncia intentando superar las dicotomías. Por un lado, la articulación de movilidades (viajes y desplazamientos sobre el territorio) e inmovilidades (trabajo de laboratorio, charlas y encuentros de sociabilidad); y por el otro, un 
mundo científico (externo) que se impone por leyes generales y por la fuerza de la racionalidad, y el mundo poético/artístico que se encuentra en la esfera del mundo subjetivo. La razón y el progreso fueron los ejes que sustentaron la "Era de la Ilustración" en la que creció el naturalista. Desde este contexto y a partir del método comparativo, Humboldt formula la unidad del cosmos desde la cual la naturaleza, en lugar de ser un mecanismo con leyes particulares para cada individuo, se constituyó en un conjunto unido y animado por fuerzas interactivas (Wulf, 2016).

Sobre la base de la lectura de Vistas de las cordilleras, y de acuerdo con los objetivos planteados, realizamos un trabajo de relevamiento de autores a fin de definir categorías de análisis que, por un lado, permitan contextualizar esta obra particular dentro de un nuevo contexto emergente y, por otro lado, que ayuden a interpretar los sentidos específicos de Vistas en relación a la singularidad de una nueva mirada sobre el Nuevo Mundo. De esta manera, conformamos una herramienta de lectura y abordaje para poder entender el valor de la obra tanto dentro de su tiempo, como su relevancia actual.

\section{ConTeXto y Reinvención de AméricA}

La primera reinvención de América supuso la existencia de dos grupos. Por un lado, las élites europeas septentrionales con vastas posibilidades expansionistas para los capitales, la tecnología, las mercancías y los sistemas de conocimiento europeos. Y, por otro lado, las nuevas elites independientes de Hispanoamérica, quienes sentían la necesidad de una auto invención en relación con las masas tanto europeas como no europeas a las que intentaban gobernar.Los escritos de Alexander von Humboldt brindaban visiones fundacionales para ambos grupos, cuestión que el naturalista aprovechó en la medida que pudo hacerlo (Wulf, 2016). ${ }^{3}$ Reinventó América del Sur como naturaleza, pero no la naturaleza accesible, recolectable, reconocible y categorizable de los linneanos, sino una naturaleza impresionante, extraordinaria, un espectáculo capaz de sobrecoger la comprensión y el conocimiento humanos. Tampoco trabajó para una naturaleza que esperase sentada a que la conozcan y posean, sino una naturaleza en acción, dotada de fuerzas vitales, una naturaleza que empequeñecía a los seres humanos, desafiando sus poderes de percepción. Y esta propuesta cobra relevancia en el contexto de una modernidad desbordante en cuanto a su manera de decodificar el mundo natural. Con la Revolución Industrial, los hombres empezaban a controlar la naturaleza a través de la imposición de la tecnología, cambiando la concepción que de ella tenían y, con ello, de su paisaje. ${ }^{4}$ Se empiezan a controlar los fenómenos de la naturaleza que hasta entonces habían sido potestad de Dios: con este poder el hombre pierde el miedo. El mundo comienza a ser previsible, siempre que la humanidad pueda desentrañar las leyes naturales. Pero Humboldt inicia un proceso inverso en relación a la decodificación del mundo natural. Si bien también intenta abordarlo desde la constitución de leyes y de identificar lo observado a una escala mundial, lo hace desde un minucioso trabajo de campo, tratando de llegar al epicentro de la naturaleza. No es algo dado, sino algo que hay que descubrir. Desde una perspectiva y metodología antropológica, podemos afirmar que Humboldt no estudió la naturaleza, sino que estudió en la naturaleza, articulando dos dimensiones emplazadas en los instrumentos científicos, las mediciones y observaciones, y en el hecho de dejarse llevar por el asombro, experimentando la naturaleza a través de los sentimientos (Wulf, 2016).

Es en el año 1802 cuando su obra y su pensamiento eclosionan. Este es el año en que logra escalar la cima del Chimborazo, volcán inactivo con forma de cúpula en la cordillera de los Andes de casi $6.400 \mathrm{~m}$ de altura, ubicado a $160 \mathrm{~km}$ de Quito (Ecuador). Este acontecimiento logra generar en él una bisagra no solo en sus obras sino en la manera de entender la naturaleza. Es allí donde aparece la escala como dimensión de análisis epistemológico y metodológico. La Tierra empieza a ser comprendida como un gran organismo vivo en que todo está relacionado. Comienza a desarrollarse una nueva visión de la naturaleza que todavía influye en nuestra forma de comprender el mundo natural. Podríamos decir que este acontecimiento presenta en su pensamiento una perspectiva holística que no solo parte de la búsqueda de relaciones, sino de la necesidad de 
pensar la naturaleza a múltiples escalas (Wulf, 2016). En ese contexto esbozó una imagen: el naturgemälde, que podría significar una "pintura de la naturaleza" pero que, al mismo tiempo, entraña la sensación de unidad o integridad. Más adelante lo definió como "un microcosmos en una página”. El naturgemälde es un dibujo con una sección transversal del Chimborazo, que era una asombrosa imagen de la naturaleza como un entramado en el que todo estaba relacionado. El diseño de esta imagen (ver figura 1) se basó en la disposición de plantas distribuidas por altitud, generando una "presentación visual de los datos". Para Humboldt la unidad no estaba en la homogeneidad, sino en la variedad.

FIGURA 1

Naturgemälde ${ }^{5}$,Tableau physique des Andes et pays voisins, en Humboldt y Bonpland (1805)

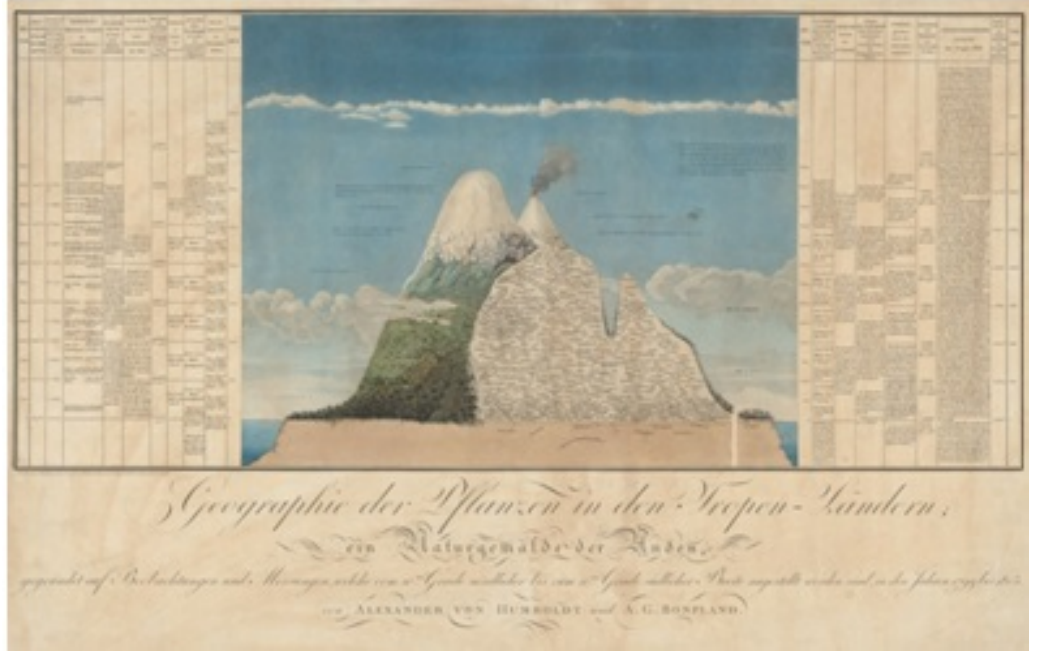

Fuente: Peter H. Raven Library/Missouri Botanical Garden, Biodiversity Heritage Library

Pero Humboldt, en este contexto, plantea miradas diferentes en varios pasajes de sus obras. Sobre todo, en la propuesta de abordaje de la naturaleza, y con ello en la mirada del "otro" como un agente social culturalmente diferente, pero no así inferior. Por lo cual se opone a una naturaleza subordinada a la modernidad y al demoledor poder de la técnica y la revolución industrial, a una naturaleza pasiva de ser descubierta o una naturaleza europea como patrón cultural de comparación y, por lo tanto, indicador de desarrollo o subdesarrollo. La mirada humboldtiana no se nutría solo del mundo científico, sino también de la imaginación. ${ }^{6}$ Podemos enmarcar sus viajes a través de diferentes regiones de América Latina y por el resto del mundoen lo que James Clifford (1999) denomina "itinerarios transculturales". Con esta propuesta conceptual, Clifford pudo referirse a los viajes y a los diferentes contactos con las culturas como situaciones cruciales para una modernidad que aún no ha terminado de configurarse. El viaje y las prácticas de desplazamiento podrían aparecer como "constitutivos" de significados culturales, en lugar de su simple extensión o transferencia (Clifford, 1999, p: 13). ${ }^{7}$ Para Humboldt, cada viaje, traslado, percance, desvío, retorno, etc., configuró una forma de habitar y comprender el mundo. Sin estos desplazamientos, su obra y pensamiento no hubieran cobrado registros transculturales.

Con los viajes y recorridos por Sudamérica, Humboldt se iría alejando de la perspectiva antropocéntrica que había regido durante milenios. Además de ponderar la naturaleza, también valoraba (a diferencia de casi todos los europeos) la población nativa indígena. Para él no se trataba de bárbaros, sino que admiraba su cultura y prácticas en relación con su entorno. Humboldt hablaba más de la "barbarie del hombre civilizado", al ver cómo trataban los colonos y misioneros a la población local. Al retornar a Europa, se llevó una imagen totalmente diferente de los llamados "salvajes". Esto lo plasmaría años más tarde en su obra Ensayo político sobre el Reino de la Nueva España, publicado en cuatro volúmenes entre 1808 y 1811, donde denunciaba los atropellos humanos y ambientales del colonialismo, y destacaba las capacidades de los indígenas por fuera de 
la estigmatización de los españoles. Advertía, además, que el futuro de la región dependía de la agricultura de subsistencia y no de los monocultivos ni de la minería.

\section{Vistas de las CORDILlerAS Y MONUMENTOS DE LOS PUEblos INDÍGENAS DE AMÉRICA}

Como resultado de su itinerario por varios países americanos, a su regreso a Europa en 1804, Humboldt publicó numerosas y extensas obras en las que expuso los resultados de sus investigaciones. Vistas de las cordilleras fue publicada en París en 1810, y se trató de un texto que contenía dos volúmenes con 69 grabados, en blanco y negro o en color, cuyos bocetos diseñó él mismo en el propio terreno de exploración. Los grabados estaban acompañados de sus correspondientes textos explicativos, más o menos extensos, en los que el naturalista se explayaba sobre los aspectos naturales y culturales del continente americano, incluso refutando o apoyando tesis previas. Esta obra constituyó una importante novedad para la época. En primer lugar, porque la publicación de las imágenes como testimonio científico y demostración era un modo sin precedentes en la literatura de viajes de entonces. En segundo lugar, porque este libro aportaba un valiosísimo análisis antropológico sobre las antiguas culturas americanas, sobre todo de México y de Perú. El objetivo de Humboldt era dar a conocer los aspectos esenciales del mundo americano, de sus culturas y de su ambiente natural, sobre la base de investigaciones científicas, de la acumulación de datos y de la exposición de imágenes de diversa índole. Vistas de las cordilleras aún a como propósito principal indagar en la historia de los pueblos y en el conocimiento de la naturaleza, reflejando la visión humboldtiana de las relaciones estrechas entre el hombre y su entorno y, por extensión, su visión global del mundo. El libro es, como dice Andrea Wulf, "una celebración de Latinoamérica a través de su mundo natural, sus antiguas civilizaciones y su gente" (Wulf, 2016, p. 179).

Según Ottmar Ette (2008), es este el proyecto de libro más radical de Humboldt: se trata de lo que Ette llama una "escritura fragmentaria" (p. 301), en donde no se sigue ningún orden geográfico, itinerario, cronológico, histórico, temático o cultural que lo ordene en una composición coherente. Pero su importancia radica en que en esta obra el naturalista desarrolla un nuevo orden mundial/cultural, basado en la comprensión de las culturas "no como un sistema cerrado, sino como una relacionalidad en movimiento" ( $\mathrm{p}$. 306). Esta noción del movimiento atraviesa la lectura que Ette hace de Vistas, concepto que según él organiza el propio discurso del libro (sistema de referencias internas), así como las redes de conocimiento (referencias externasentre otras obras y disciplinas) y la relación de las culturas (americanas y europeas) dentro de su nuevo orden mundial.

Las descripciones de este libro dedicadas a lo que Humboldt llama "vistas pintorescas" (vuespittoresques) (Humboldt, 1995, p. 7) ${ }^{8}$ representan, junto con los grabados que acompañan, ejemplos potentes de su percepción de la naturaleza americana, a partir de nociones estéticas. Por ello, y a la luz de las teorías actuales, la traducción podría ser paisajes en lugar de vistas pintorescas. A la idea (ya presente en el idealismo alemán) de la totalidad sobre la diversidad de los elementos, en la concepción humboldtiana cobra mayor peso el de la influencia de la naturaleza en la sensibilidad del hombre, "donde el aspecto estético y el paisaje entendido desde esta óptica comienzan a tomar relevancia” (Corbera Millán, 2014, p. 49). ${ }^{9}$ Gómez Mendoza (2010) explicita que fue durante el romanticismo que nació la "naturaleza-paisaje", "entendido el paisaje como naturaleza estéticamente presente, que se muestra al ser que la contempla con sentimiento" (2010, p. 50). Teniendo en cuenta la idea de "totalidad", más abajo afirma que "es la correspondencia, la consciencia del todo al encadenar los elementos, la que 'crea' el paisaje” (p. 50).

En su afán por representar aunque sea "fragmentos de monumentos americanos" (Humboldt, 2012, p. 33), los grabados y las descripciones relativas a los entornos naturales que enmarcan a aquellos están dominados por la estética del goce, enfocada en una sensibilidad azorada por los lugares que le tocó presenciar. Una subjetividad contemplativa se deja subyugar por la majestuosidad del paisaje montañoso, y la terminología 
asociada a lo asombroso, colosal, bello, salvaje, abunda en estas descripciones. Como muestra el ejemplo que sigue, en donde inclusive el observador esboza la idea de lo sublime ante el paisaje cordillerano:

Los valles de las cordilleras andinas nos ofrecen los parajes más salvajes y los más dignos de subyugar el alma con la admiración y el espanto. Son hendiduras de fondo y bordes cubiertos por una vegetación vigorosa, a menudo de una profundidad tan grande que pudieran contener el Vesubio y el Puy de Dome sin que sus cimas destacaran sobre el telón de las montañas (Humboldt, 2012, p. 39).

La naturaleza americana que Humboldt redescubre es una novedad para la imaginación europea de entonces. Si antes estaba dominada por la idea de inferioridad (sobre todo, derivada de las teorías de Buffon), ahora adquiría nuevas dimensiones: una naturaleza en estado puro, sin interferencia de la mano del hombre, lugar donde aquel "primer goce" se manifiesta en su máxima inmediatez (Vericat, 2009, p. 151). Pratt (2011) afirma que la recepción de los escritos de Humboldt en Europa implicó una selección y una reducción de la mirada de América: principalmente, como "naturaleza virgen”, compuesta de tres imágenes representativas: bosques tropicales, montañas nevadas y llanuras extensas. Tal como el título lo indica, a las montañas y a las llanuras dedica sobre todo este libro. Y estas en relación a las culturas precolombinas y su arte. Dice Humboldt en la Introducción a Vistas:

Para conocer debidamente el origen de las artes, es necesario estudiar la naturaleza de los parajes que las vieron nacer. Los únicos pueblos americanos en los que encontramos obras notables son los pueblos de la montaña. Aislados en la región de las nubes, encaramados a las mesetas más elevadas del mundo y rodeados de volcanes cuyos cráteres son vecinos de los hielos perpetuos, estos pueblos no parecen admirar, en la soledad de estos desiertos, otra cosa que lo que excita la imaginación por la enormidad de las masas. Las obras que han creado llevan el sello de la salvaje naturaleza de las cordilleras (Humboldt, 2012, p. 34).

De la totalidad del libro, aproximadamente quince (15) son las láminas que representan aspectos particulares de la naturaleza americana. Tal como dijimos, no tienen orden aparente ni coherencia, salvo en el sentido de que resultan significativas como ejemplos particulares de la majestuosidad de las montañas, de su belleza, de la variedad de su vegetación y de la peculiaridad del paisaje total. Las explicaciones que las acompañan están narradas con una mezcla de lenguaje científico (aporta datos específicos sobre alturas, formaciones geográficas, formaciones rocosas, etc.) y un lenguaje que se carga del asombro ante aquello que el observador contempla.Se trata del narrador-viajero, que relata desde una experiencia prácticamente inusual, siendo el que en efecto captó esa naturaleza con los sentidos y con una mirada aguda, atenta a los detalles y a las relaciones, dispuesta al análisis y, sobre todo, a la exaltación de la sensibilidad. Humboldt expone una mirada personal sobre América, a través de diferentes estrategias discursivas que incluyen no solo la descripción y el análisis científico, sino también la comparación entre Europa y América o entre diferentes regiones geográficas del planeta. También desmitificaciertas creencias populares acerca de posibles peligros o mitologías enraizadas, así como expone una crítica abierta a ciertas formas habituales de tratar a los nativos (por ejemplo, en el caso de los llamados "cargueros") y hace varias referencias a una naturaleza útil, al servicio del hombre (plantas útiles).

En esta nueva manera de mostrar América a Europa, la imagen se convierte en un medio indispensable. Asociar la ciencia a la estética fue el trabajo central en Humboldt, lo que según Corbera Millán (2014) lo lleva a utilizar dos recursos fundamentales: un estilo literario, asociado a descripciones animadas del paisaje, y las imágenes propiamente dichas, las que en su tiempo se limitaban a la pintura y el grabado ${ }^{10}$. De ahí que Vistas de las cordilleras impresione sobre todo por la calidad de las representaciones pictóricas de determinados paisajes naturales americanos, zonas de montañas, volcanes, cascadas, llanuras, etc., que tienen la intención de magnificarlas y representarlas en sus justas proporciones. Lo que se nota en el libro es el asombro ante un paisaje majestuoso. Las vistas son imponentes; las alturas, colosales; la perspectiva favorece una percepción más exacta del tamaño inmenso de las montañas. En los grabados del libro, la representación de los viajeros en medio del paisaje da cuenta del tamaño y de las características del entorno: en general, aparecen muy pequeños 
en relación a él, y rodeados de inmensas formaciones rocosas, cuando no de abundante vegetación o enormes llanuras prácticamente desérticas. De la vieja tradición europea sobre la "inferioridad" del continente, o de una mirada que hasta le atribuía rasgos míticos, el pensamiento de Humboldt sobre América se distanció del pensamiento buffoniano, le dio entidad científica, y la magnificó en Vistas.

FIGURA 2

El Chimborazo.

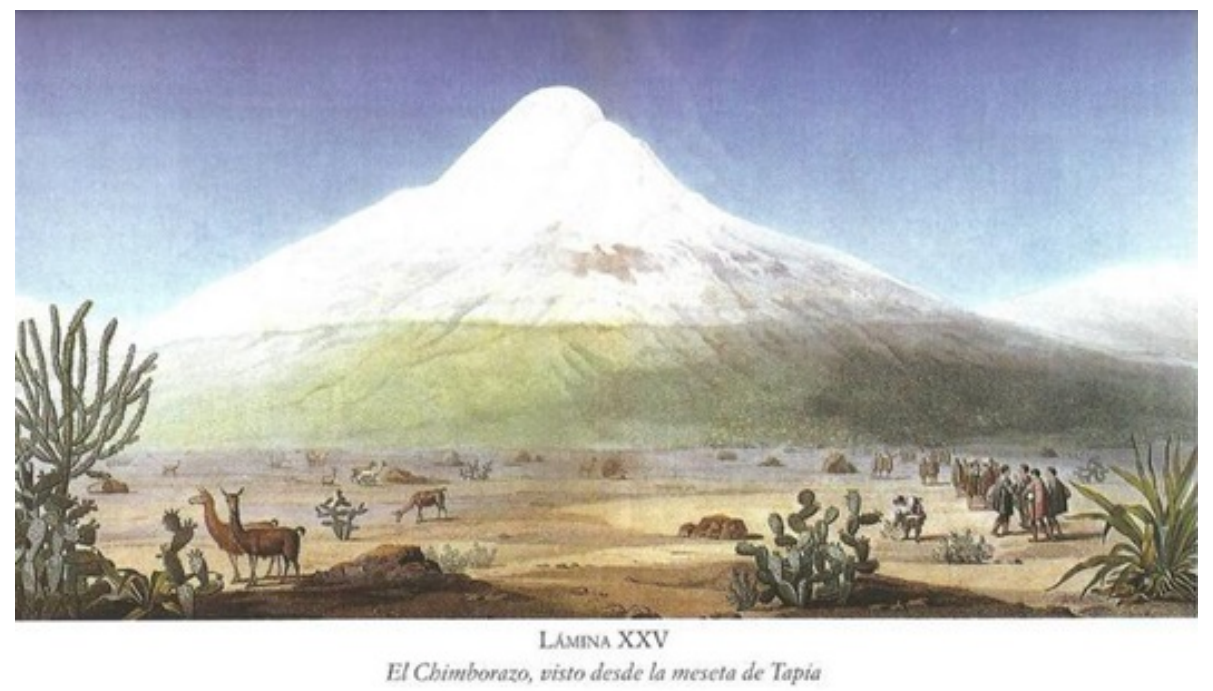

Vistas de las cordilleras y monumentos de los pueblos indígenas de América. Fuente: Alexander von Humboldt (2012) 
FIGURA 3

Puentes naturales de Icononzo

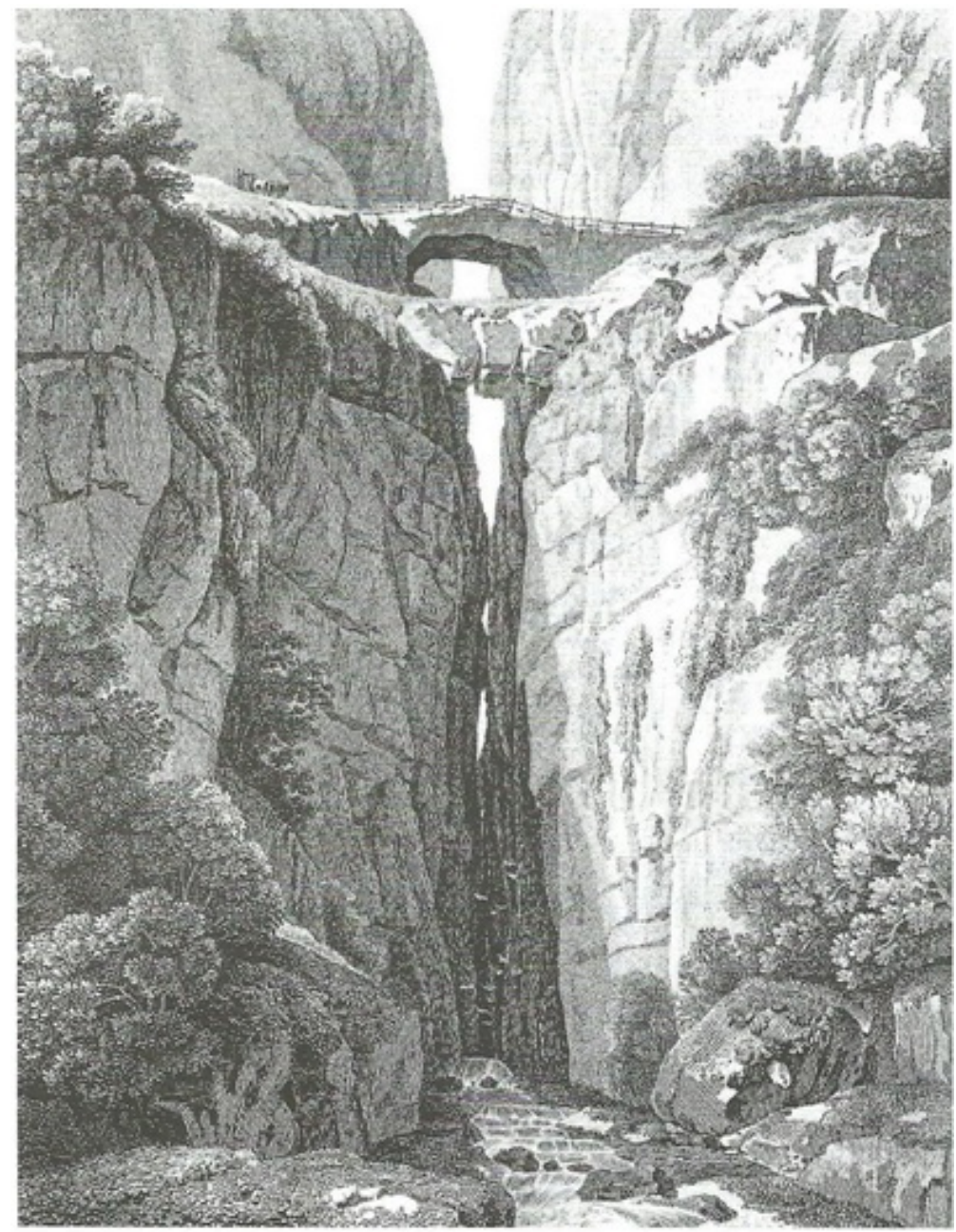

LÁMINA IV

Puentes naturales de Icononzo

Vistas de las cordilleras y monumentos de los pueblos indígenas de América Fuente: Alexander von Humboldt (2012)

En las páginas preliminares, Humboldt da cuenta de su tesis acerca de la relación entre la cultura y el ambiente natural. Asume que las características geográficas de los pueblos inciden de manera profunda en las de las artes que desarrollan. Así, mientras afirma que "para conocer debidamente el origen de las artes es necesario estudiar la naturaleza de los parajes que las vieron nacer” (p. 33), está convencido de que;

el clima, la configuración de los suelos, la fisonomía de la vegetación y el carácter risueño o salvaje de la naturaleza influyen en el progreso de las artes y en el estilo que distingue sus creaciones. Esta influencia es tanto más manifiesta cuanto que el hombre se encuentra alejado de la civilización (p. 33).

De esta manera, Humboldt estudia el arte de las antiguas civilizaciones precolombinas, al que califica de "tosco" e "incorrecto", según la influencia que sobre los pueblos tuvo una relativa soledad en medio de una naturaleza salvaje e inestable. 


\section{LAS CULTURAS AMERICANAS DESDE UNA NUEVA PERSPECTIVA}

Charles Minguet (1995) afirma que esta obra buscaba, sobre todo, reflexionar en torno de una pregunta fundamental: ¿cómo integrar aquel nuevo mundo desconocido y extraño a las concepciones europeas de la historia de la evolución antropológica e histórica universal? Las Vistas de las cordilleras significan un valioso aporte al estudio antropológico de América. Según sostiene Minguet en otro trabajo (2001), Humboldt superó la vieja dicotomía entre naciones bárbaras y civilizadas, e insistió en la especificidad de cada cultura, integrando a los pueblos precolombinos dentro de una historia universal de la humanidad. $Y$ en su tarea como antropólogo y naturalista, ambos aspectos del mundo americano ocupan posiciones diferentes. Jaime Labastida afirma que, mientras en Humboldt el paisaje adquiere relevancia estética, las impresiones que le dejan los monumentos precolombinos no tienen el mismo estatuto. No los considera por su belleza, sino por su importancia histórica; entonces, para medir sus juicios de valor "su criterio estético está apoyado sobre los nódulos del arte clásico o, en otro sentido, el neoclásico de su época” (Labastida, 1995, p. 28).

Por esto, Humboldt no podía desprenderse de ciertos criterios sobre todo estéticos que permeaban el análisis de los pueblos americanos. Una pregunta surge entonces: ¿Bajo qué parámetros perceptivos observaba y analizaba Humboldt la cultura, y más específicamente, el arte mexicanos? Dado el lugar que en el libro ocupan los monumentos interpretados como obras artísticas, ¿cómo analizaba al "otro" indígena americano, si tenemos en cuenta el modelo de la "similitud" (Adorno, 1988)? Umberto Eco analiza el concepto de belleza en la Antigüedad, aunque admite que lo que actualmente recibimos como un ideal de belleza clásico es "una imagen estereotipada del mundo griego, nacida de la idealización que de la civilización griega se hizo en la época neoclásica" (Eco, 2013, p. 23). De acuerdo con el arte escultórico griego, para el cual la proporción y la simetría eran reglas básicas (Eco, 2010, p. 41), Eco sostiene que:

es natural que, partiendo de esta idea de belleza, se consideraran feos todos aquellos seres que no se adecuaban a estas proporciones. Pero si los antiguos idealizaron la belleza, el neoclasicismo idealizó a los antiguos, olvidando que estos (influidos a menudo por tradiciones orientales) también transmitieron a la tradición occidental imágenes de una serie de seres que eran la encarnación misma de la desproporción, la negación de todo canon (Eco, 2013, p. 23).

A la luz de lo expuesto acerca de los parámetros perceptivos clásicos, y luego del análisis de las láminas y textos del libro -análisis que excede los límites de este trabajo-, hemos concluido que cuando se trata de los monumentos mexicanos, abundan en Vistas de las cordilleras las referencias a un "arte tosco", desproporcionado, incorrecto, infantil, asociado a lo sanguinario, salvaje, bárbaro, etc., que ciertos aspectos culturales de aquellos pueblos demostraban en los sacrificios o en la ausencia de un alfabeto suplido por una serie de jeroglíficos que, según el naturalista, solo daban cuenta del atraso al que se habían visto sometidos.

\section{REFLEXIONES FINALES}

La propuesta de Humboldt sobre la "invención” de la naturaleza nos invita a reflexionar sobre tres ejes:

1 - El viaje

2 - La relación entre la ciencia y la imaginación

3 - El habitar la naturaleza como huésped y no como propietario

La naturaleza que el autor configura en sus obras ha sidonovedosa en su tiempo, tanto por los descubrimientos realizados, como por el hecho de diferenciarse de otros autores de su época.Su voraz apetito por el descubrimiento y su tenaz capacidad descriptiva le permitieron construir una bitácora de viaje pormenorizada que complementó con su trayectoria intelectual. El estatuto y la entidad que le otorga al mundo natural desde una postura de "aprendiz y curioso" le permiten presentar un escenario complejo, lleno de energía y dinamismo. Esta postura de "conocedor que quiere conocer" brinda a sus obras una 
naturaleza que requiere ser (re) descubierta, pero que a su vez necesita del sujeto que la ordene, la sistematice y la presente. Una naturaleza no para ser dominada, sino para ser comprendida. Sus obras marcan una continuidad y perdurabilidad contemporáneas. Por ello esta propuesta intentó abordar sus perspectivas de manera articulada a través de la relación antes mencionada. Consideramos que de esta manera podemos comprender no solo los resultados alcanzados y esgrimidos, sino también las metodologías que configuraron su obra. El viaje como un desplazamiento e itinerante transcultural que nutre la observación en contacto con el territorio y todas sus dimensiones. La relación de la ciencia (moderna) e imaginación como constructos epistemológicos. Y, por último, la capacidad de habitar la naturaleza desde adentro, tratando de decodificar sus fuentes desde una propuesta inductiva.

Por otra parte, en Vistas de las cordilleras específicamente, la naturaleza se asocia a una sensibilidad dispuesta a sorprenderse ante paisajes que solo se describen y representan como majestuosos y subyugantes. La intención es específica y clara, según el propio Humboldt: estudiar los monumentos pertenecientes a las culturas precolombinas en relación con su entorno, un entorno "salvaje" y colosal que empequeñece al hombre y le enseña nuevas perspectivas. En cuanto a las culturas americanas, aunque su racionalismo le impida comprender muchos aspectos culturales, y aunque no pueda salirse de esquemas europeos (y, por extensión, clásicos), su postura frente al universo cultural que estudia es más amplia que la de sus predecesores y anticipa de alguna manera la antropología posterior. Así, comprende que el camino hacia la civilización no es un tránsito uniforme ni desprovisto de altibajos. Y que en todas las culturas del planeta, más o menos civilizadas, hay tanto para rescatar como para desechar. Entiende a la humanidad como nacida de un mismo germen, pero valora lo que cada pueblo es en sí mismo. En este sentido, eleva el continente americano, quitándolo del lugar de "tabula rasa" o de "extensión” de las culturas antiguas de Asia, Europa o el Oriente.

\section{REFERENCIAS}

Adorno, R. (1988). El sujeto colonial y la construcción cultural de la alteridad. Revista de crítica literaria latinoamericana, 14(28).

Barrera Lobatón, S. y Monroy Hernández, J. (eds.) (2014). Perspectivas sobre el paisaje. Bogotá: Universidad Nacional de Colombia.

Clifford, J.(1999). Itinerarios transculturales. Barcelona, España. Editorial Gedisa.

Corbera Millán, M.(2014). Ciencia, naturaleza y paisaje en Alexander von Humboldt. Boletín de la Asociación de Geográfos Españoles, 64, 37-64.

Collot, M. (2011). La Pensée-paysage. París: Actes Sud/ENSP.

Dardel, E. (2013). El Hombre y la Tierra: Naturaleza de la realidad geográfica. Madrid, España. Editorial Biblioteca Nueva.

Eco, U. ([2004] 2010) Historia de la belleza. Buenos Aires: Ed. Debolsillo.

Eco, U. ([2007] 2013) Historia de la fealdad. Buenos Aires: Ed. Debolsillo.

Ette, O. (2008). Las dimensiones del saber (geográfico). Los cuadros de la cultura de Alejandro von Humboldt. En Cuesta Domingo, M. y Rebok, S. (eds.), Alexander von Humboldt. Estancia en España y viaje americano. Madrid: Consejo Superior de Investigaciones Científicas.

Gómez Mendoza, J.y Sánz Herráis, C. (2010). De la biogeografía al paisaje en Humboldt: pisos de vegetación y paisajes andinos equinocciales. Población y sociedad, 17, 29-57.

Humboldt, A.V. (2012). Vistas de las cordilleras y monumentos de los pueblos indígenas de América. Universidad Autónoma de Madrid. Madrid: Marcial Pons Historia.

Labastida, J. (1995) Las aportaciones de Humboldt a la antropología mexicana. Estudio preliminar. En Humboldt, A. ([1810] 1995), Vistas de las cordilleras y monumentos de los pueblos indigenas de América. México: Siglo XXI. 
Levy, B. (2016). Geografía y Literatura. En Daniel Hiernaux y Alicia Lindon (dir.), Tratado de Geografia Humana (pp. 460-480).Editorial Anthropos. Universidad Autónoma Metropolitana.

Minguet, Ch. y Duviols, J. P. (1995). Una obra maestra del americanismo: las Vistas de las cordilleras de Alejandro de Humboldt. En Humboldt, A. ([1810] 1995), Vistas de las cordilleras y monumentos de los pueblos indigenas de América. México: Siglo XXI.

Minguet, Ch. (2001) Una nueva imagen de la América española: la obra de Alejandro de Humboldt (1805-1850). En Zea, L. y H. Taboada (comp.) (2001) Humboldt y la modernidad. México: Fondo de Cultura Económica.

Pratt, M.L. (2011). Ojos imperiales. Literatura de viajes y transculturación. México. Editorial Fondo de Cultura.

Said, E. ([1979] 2002). Orientalismo. Barcelona, España. Editorial Debolsillo.

Vericat, J. (2009). Imágenes sin texto. La visión y el arte en los Cuadros de la naturaleza de Alexander von Humboldt. En Fermín del Pino Díaz, Pascal Riviale, Juan José Villarías Robles (editores) Entre textos e imágenes: representaciones antropológicas de la América indígena. Madrid: Consejo Superior de Investigaciones Científicas (Libro digital).

Wulf, A. (2016).La invención de la naturaleza. El nuevo mundo de Alexander Von Humboldt. Buenos Aires: Editorial Taurus.

\section{Notas}

1 Este trabajo se desprende, con algunas variantes, de la ponencia "Humboldt y la construcción del paisaje latinoamericano. Una mirada entre la literatura y la geografía”, presentado en las XIX Jornadas de Investigación y Enseñanza de la Geografía organizadas por el Centro de Investigaciones Geográficas y el Departamento de Geografía de la Facultad de Humanidades y Ciencias de la Educación de la Universidad Nacional de La Plata, el 15 de noviembre de 2017, y fue realizado en el contexto del PID H805-UNLP, "Paisajes: naturaleza y cultura en la literatura latinoamericana (siglos XIX y XX). Algunas inflexiones" (2017-2018).

2 Este trabajo se desprende, con algunas variantes, de la ponencia "Humbold y la construcción del paisaje latinoamericano. Una mirada entre la literatura y la geografía", presentado en las XIX Jornadas de Investigación y Enseñanza de la Geografía organizadas por el Centro de Investigaciones Geográficas y el Departamento de Geografía de la Facultad de Humanidades y Ciencias de la Educación de la Universidad Nacional de La Plata, el 15 de noviembre de 2017, y fue realizado en el contexto del PID H805-UNLP, "Paisajes: naturaleza y cultura en la literatura latinoamericana (siglos XIX y XX). Algunas inflexiones" (2017-2018).

3 Humboldt era consciente de que debía moverse con cautela y lucidez entre las altas esferas americanas, no solo las del sur sino, sobre todo, en la nación reciente y pujante del norte que tanto admiraba. Como se sabe, el naturalista exhibió sin mezquindades datos recabados, información, pero en especial los nuevos mapas que había confeccionado sobre México, anteel presidente de los Estados Unidos, Thomas Jefferson, con quien se encontró en Washington poco antes de volver a Europa (Wulf, 2016, pp. 129 y ss.).

4 Tenemos presente, por supuesto, la diferencia entre naturaleza y paisaje. La bibliografía es amplia, pero en este texto, consideramos relevantes los aportes efectuados en Barrera Lobatón y Monroy Hernández (2014) y Collot (2011).

5 Como advertimos, esta representación gráfica nace de haber escalado el Chimborazo y de llegar a su cima. Esta acción le permitió tener otra escala de la realidad, pudiendo identificar una naturaleza diversa, estratificada y estrechamente relacionada. Humboldt no veía las plantas dentro de estrictas categorías de una estratificación, sino como tipos en función de la situación y el clima. Para él la naturaleza era una fuerza global con zonas climáticas correspondientes en todos los continentes, siendo este un concepto radical para su época. La naturaleza como una red de vida que empujaba para hacer un lugar.

6 La imaginación y la naturaleza logran entrelazarse a partir de la relación de Humboldt y Johann Wolfgang von Goethe. Si bien Goethe provenía y se destacaba en las artes, era un científico apasionado por la formación de la Tierra y la botánica. Escribió un ensayo, "La metamorfosis de las plantas", donde sostenía la idea de que existía una forma arquetípica o primordial que servía de base al mundo vegetal. Con la llegada de Humboldt pudo desarrollar sus teorías, o al menos discutirlas. Goethe distinguía entre la fuerza interna que proporcionaba la forma general de un organismo vivo y el entorno (la fuerza externa) que moldeaba ese organismo. Es en este encuentro entre Humboldt y Goethe donde nace la impronta humboldtiana de comprender la naturaleza en una síntesis científico-artística.Muchos años más tarde, según el geógrafo Eric Dardel, la Geografía debe mantenerse en la encrucijada de dos mundos: el físico y el humano. En sus obras recurre a la literatura por dos razones: ella simboliza la escritura de la Tierra, la delineación de las riberas, los recortes de la montaña y las ondulaciones del río. Y, por otro lado, se convierte en la expresión de una vivencia humana, de una 
vinculación con los lugares y con los elementos de la naturaleza. Su obra titulada El Hombre y la Tierra: Naturaleza de la realidad geográfica (1952) se opone al de la tecno-ciencia que sustenta fuertemente la geografía científica. Tampoco se funda en reproducir las divisiones clásicas entre la Geografía Física, por un lado, y la Geografía Humana, por el otro. Su propuesta intenta evitar dicha escisión para conectar al lector en un abordaje más profundo de la realidad de la naturaleza y el hombre. El universo que expone Dardel nos pone en una necesaria relación entre el mundo exterior e interior. Hablamos de una objetividad enraizada en una subjetividad que se inscribe en una perspectiva fenomenológica, desarrollada más tarde por la geografía humanista (Lévy, 2016). Dardel se pregunta: ¿quién tiene razón? Para él existe una verdad manifiesta de las apariencias, porque estas no son ilusiones, sino la "fisonomía" del fenómeno, y a dicha fisonomía solo se puede acceder en el marco de un encuentro estético: resonancia de la imagen poética.

7 Para Clifford el trabajo de campo se describe como un espacio abierto y desbrozado. Pensando en clave las relaciones cambiantes de la antropología y el viaje, puede ser útil pensar en el campo como un "habitus", más que como un lugar; un conjunto de disposiciones y prácticas “corporizados". Mary LouisePratt (2008) plantea el concepto zona de contacto como espacios sociales donde culturas dispares se encuentran, chocan y se enfrentan a menudo dentro de las relaciones altamente asimétricas de dominación y subordinación. Pero si bien Humboldt habitó dentro de esta zona de contacto (en palabras de Pratt) en Sudamérica, se reposicionó de manera diferente a otros viajeros que partieron de una mirada orientalista (Said, 1979, 2002).

8 La obra que se ha considerado en su idioma original a partir de la siguiente edición: Humboldt, Alexander von (1810 [1995]).Vues des cordillères et monuments des peuplesindigènes de l'Amérique. Paris: Schoell. Digitalizada por Gallica de la Bibliothèque Nationale de France y disponible en http://gallica.bnf.fr/ark:/12148/bpt6k61301m.r=.langEN (21/7/2010). Hemos optado, sin embargo, por citar su traducción en español de la siguiente edición: Humboldt, Alexander von (2012).Vistas de la cordilleras y monumentos de los pueblos indígenas de América. Traducción de Gloria Luna Rodrigo y Aurelio Rodríguez Castro. Estudio preliminar de Nicolás Ortega Cantero. Madrid: UAM - Marcial Pons. También se ha consultado: Humboldt, Alexander von (1995).Vistas de las cordilleras y monumentos de los pueblos indígenas de América. Prólogo de Charles Minguet y Jean-Paul Duviols. Introducción, traducción y notas de Jaime Labastida. Notas de Eduardo Matos Moctezuma, Mercedes Olivera y Cayetano Reyes. México: Siglo XXI.

9 Para Humboldt se trata de un proceso de conocimiento, que puede interpretarse en el sentido de un movimiento de lo exterior a lo interior, y que consta de tres instancias, a las que el científico denomina "goces": un "primer goce", que consiste en la intuición de la unidad y la armonía al primer contacto del hombre con la naturaleza; un "segundo goce", que tiene que ver sobre todo con la evocación de un paisaje vivido; y un "tercer goce", que se deriva del conocimiento de las leyes y de las relaciones entre los fenómenos (Corbera Millán, 2014, p. 49).

10 Si hubiese existido la fotografía, seguramente hubiera reemplazado los grabados por fotos. Las imágenes tienen valor testimonial, pero también traducen el modo de ver en el que imperan los regímenes perceptivos europeos. 